\title{
Impact of urbanization on boundary layer structure in Beijing
}

\author{
Miao Yu • Yimin Liu • Yifeng Dai • Aqiang Yang
}

Received: 26 October 2012 / Accepted: 6 May 2013 /Published online: 1 June 2013

(C) The Author(s) 2013. This article is published with open access at Springerlink.com

\begin{abstract}
The Beijing meteorological tower is located in an area of Beijing, China, which has developed from a suburban to an inner city setting over the past 30 years. The impacts of this urbanization process on both the vertical profile and diurnal cycles of air temperature are investigated using hourly data collected from a series of monitoring levels (up to $325 \mathrm{~m}$ high) on the Beijing meteorological tower since 1984. We find that the inter-decadal temperature has increased gradually, and that a more significant increase occurred during the 1980s and 1990s due to the effects of urbanization. A well-defined change in temperature stratification was also observed over this period. The height of the temperature inversion layer decreased from the 1980 s to the 2000 s. A well-defined nighttime temperature inversion developed below $50 \mathrm{~m}$ during the summer in the $1980 \mathrm{~s}$, but this near-surface inversion is not seen in data from the 1990s and 2000s. This change can be related to an increase in turbulent mixing caused by urban roughness and surface heat storage that disturbs the nearsurface temperature inversion layer. In addition, the diurnal change in temperature in the city in summer shows a maximum increase from sunrise to the early afternoon, which is mainly caused by the nature variability and global warming in both the summer and winter. The urbanization mainly contributes to the temperature increase in the afternoon and nighttime. Moreover the urbanization dominates the increase in daily mean near-surface temperature.
\end{abstract}

Electronic supplementary material The online version of this article (doi:10.1007/s10584-013-0788-2) contains supplementary material, which is available to authorized users.

M. Yu $\cdot$ Y. Liu $(\bowtie) \cdot$ Y. Dai

State Key Laboratory of Numerical Modeling for Atmospheric Sciences and Geophysical Fluid Dynamics, Institute of Atmospheric Physics, Chinese Academy of Sciences, Beijing 100029, China e-mail: lym@lasg.iap.ac.cn

M. Yu • Y. Dai

University of Chinese Academy of Sciences, Beijing 100049, China

A. Yang

Institute of Remote Sensing Applications, Chinese Academy of Sciences, Beijing 100101, China 


\section{Introduction}

Considerable evidence suggests that the extensive land use and land cover change (LULCC) associated with the rapid progress of global urbanization has a significant impact on regional climate. Local and regional atmospheric features, especially the planetary boundary layer (PBL) structure, have been altered significantly. Bornstein (1968) identified the well-known urban heat island (UHI) effect, in which the temperature of the near-surface air and the ground in urban areas are higher than in surrounding rural areas. Oke (1995) proposed a relatively comprehensive theory covering the characteristics, causes and effects of the UHI. The impact of urbanization has also been estimated by comparing observed surface temperatures with the corresponding trends in the NCEP/NCAR reanalysis (NNR) data, which are insensitive to surface observations over land (Kalnay and Cai 2003). The same method was used to analyze the impact of land-surface forcing on temperature trends in the eastern United States. The results imply that the impact of greenhouse gases is more important during the winter, whereas surface forcing dominates through the summer (Kalnay et al. 2006).

The Beijing metropolitan area, which is one of the 10 largest megacities globally, has experienced unprecedented and rapid urbanization over the past 30 years, and there has been considerable research interest in this process and its impacts. Yan et al. (2009) analyzed a series of temperatures recorded in Beijing at a height of $2 \mathrm{~m}$ from 1977 to 2006 to determine the effects of site change (of the monitoring station) and urbanization on local climate. Their results indicate that the urbanization-related warming in the Beijing temperature record was between $0.20{ }^{\circ} \mathrm{C} /$ decade and $0.54{ }^{\circ} \mathrm{C} /$ decade. This urbanization-induced warming in Beijing accounted for around $65 \%$ to $80 \%$ of the overall warming between 1961 and 2000 (Ren et al. 2007). Changes in land use may also reduce the range of diurnal temperature variations, and alter the annual variation in extreme temperatures (Hu et al. 2010). The UHI effect is strongest during the nighttime in Beijing, but may also develop during the day in the summer (Zhang et al. 2005; Dai et al. 2011). However, daytime UHI shows distinctive seasonal variations, reaching a maximum during summer. Nighttime UHI shows much less seasonal variation, reaching its maximum in winter (Wang et al. 2007). In addition to observational data, modeling has also been used to analyze the UHI and other urbanization effects (Miao et al. 2009).

Data collected at the Beijing meteorological tower is one of the most important datasets used to study the impact of urbanization. Xu et al. (2009) used data obtained from the tower, which is $325 \mathrm{~m}$ high, to analyze changes in the summer atmospheric boundary layer from 1993 to 2003. They found that the vertical decreasing rate of temperature is in increase over this period, indicating the urbanization influence on the thermodynamic structure of the boundary layer. Al-Jiboori and $\mathrm{Hu}$ (2005) assessed surface roughness around the Beijing meteorology tower and its effect on urban turbulence between 10 and 20 April 2000. In addition, tower data were also used to determine the height of the stable boundary layer (Vickers and Mahrt 2004).

However, most previous studies on vertical profile from tower data focus on short time scale (several hours to days) weather processes (dust storms and extreme high temperatures). Little attention has been paid to the inter-annual and inter-decadal variability of temperature changes related to urbanization.

The location of the Beijing tower is a typical site that experienced the urbanization process, as it has developed from a suburban to an inner city environment over the past 
30 years. In addition, using data from a single station avoids the introduction of variables associated with changes in location, instrumentation and protocols used at different sites. This study uses temperature data to determine changes of the structure of the boundary layer. The analysis includes inter-annual trends, vertical profile changes and diurnal variation trends in the variables. Our aims are:

1) to define temperature variability over the past 30 years and assess the contribution from urbanization; and

2) to develop an improved understanding of urban-related impacts on the properties of the PBL.

Details of the data and methods used are given in Section 2. Analysis of the inter-annual variation and trends are contained in Section 3, while decadal variations in vertical profiles and diurnal cycles of temperature are examined in Sections 4 and 5, respectively. We summarize our findings and present our conclusions in Section 6.

\section{Data and methods}

Beijing is located in the northern China. The data used in this study were obtained from the Beijing meteorological tower $\left(39.97^{\circ} \mathrm{N}, 116.37^{\circ} \mathrm{E}\right)$, which is $325 \mathrm{~m}$ high and located in North Beijing. The Beijing tower was established in 1978 by the Institute of Atmospheric Physics (IAP), Chinese Academy of Sciences (CAS). Data collection during the 1980s was not continuous, and the records from that period are incomplete; adequate records began in 1991. Consequently, the 1980s are represented by data from only 2 years (1984 and 1987) for which the records are relatively complete. Temperature is measured at 15 levels $(8 \mathrm{~m}$, $15 \mathrm{~m}, 32 \mathrm{~m}, 47 \mathrm{~m}, 63 \mathrm{~m}, 80 \mathrm{~m}, 102 \mathrm{~m}, 120 \mathrm{~m}, 140 \mathrm{~m}, 160 \mathrm{~m}, 180 \mathrm{~m}, 200 \mathrm{~m}, 240$ m, $280 \mathrm{~m}$, and $320 \mathrm{~m}$ ).

During the 1980s the tower was located in the outskirts of Beijing and there were no buildings over $20 \mathrm{~m}$ in height within $1 \mathrm{~km}$ of it. Consequently, the surface characteristics were those of the underlying inhomogeneous suburban surface (Peng and Hu 2006). However, Beijing has experienced rapid urbanization and dramatic economic growth since the 1990s. Many new buildings have been constructed around the tower. The Guanchengyuan residential community is $100 \mathrm{~m}$ away from the tower and may have had a significant impact on observations. Its construction started at 1993. The height of this building, located to the south of the tower, is $80 \mathrm{~m}$. The meteorological tower has recorded the process of change from a suburban surface to a rough city surface. For simplicity, we have divided our data into three periods: the 1980s, 1990s, and 2000s.

One problem associated with the analysis of temperature time series from the Beijing tower is the lack of a similar tower located in the surrounding rural areas, as the best way to demonstrate the impact of urbanization would have been to highlight the differences between data from the two towers. There is a meteorological tower located at Xianghe $\left(39.78^{\circ} \mathrm{N}\right.$, $\left.116.95^{\circ} \mathrm{E}\right)$, a rural area between Beijing and Tianjin. Temperature is measured at 7 levels $(8 \mathrm{~m}, 16 \mathrm{~m}, 32 \mathrm{~m}, 48 \mathrm{~m}, 63 \mathrm{~m}, 80 \mathrm{~m}, 100 \mathrm{~m})$. However the continuous observations in Xianghe tower only began there in 2009. Consequently, we have to use the temperature, recorded at a height of $2 \mathrm{~m}$, from three rural meteorological stations near Beijing, namely, Xiangyunling $\left(39.73^{\circ} \mathrm{N}, 115.73^{\circ} \mathrm{E}\right)$, Tanghekou $\left(40.73^{\circ} \mathrm{N}, 116.63^{\circ} \mathrm{E}\right)$, and Zhaitang $\left(39.97^{\circ} \mathrm{N}, 115.68^{\circ} \mathrm{E}\right)$ since 1980s. The land cover map (Fig. 1) got from the landsat data shows the exact location and land use type of above stations. The Beijing tower is surrounded by buildings since 1990, 

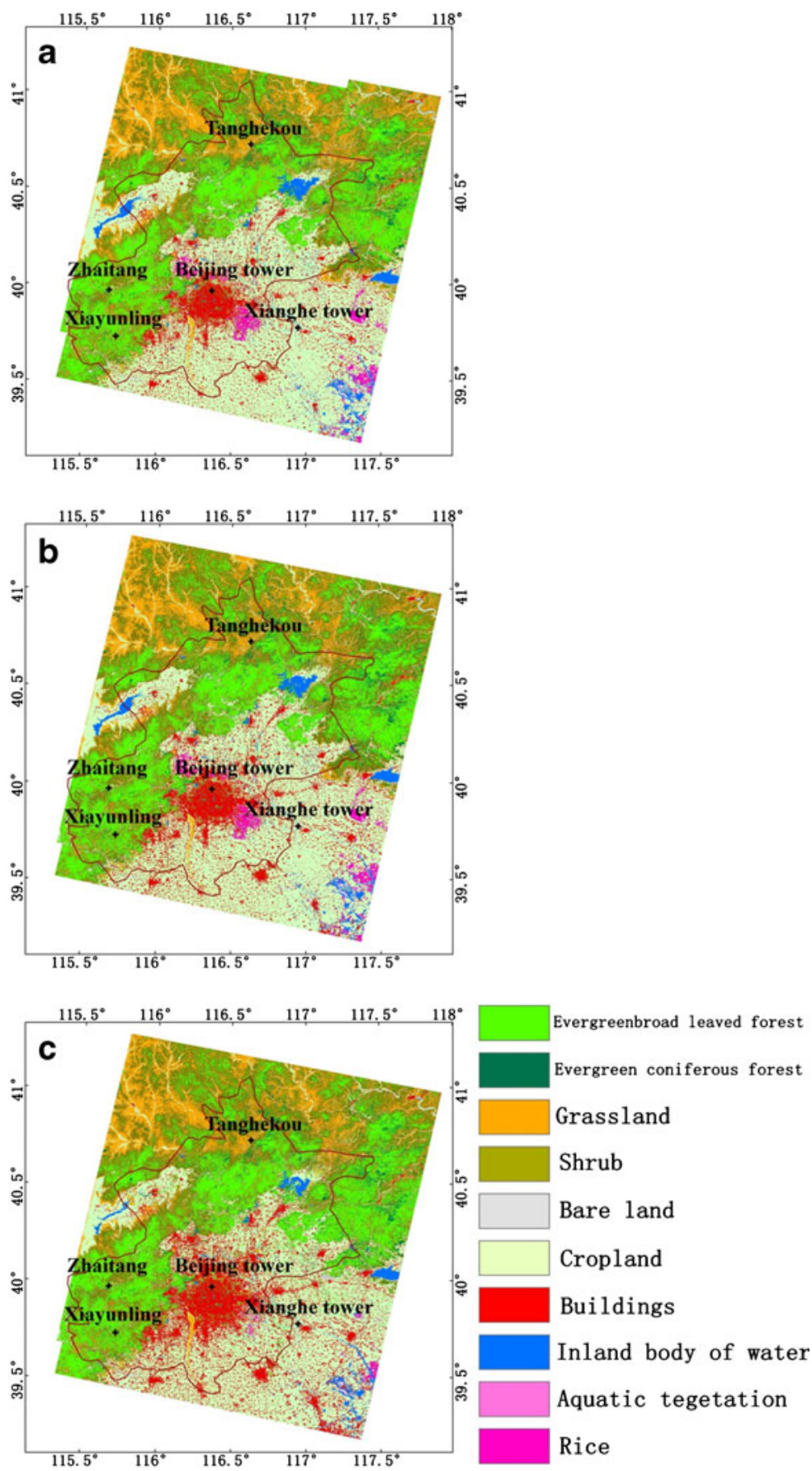

Fig. 1 Beijing land cover map in a 1990, b 2000 and c 2010. Multi-temporal remote sensing classification method is used to interpret the remote sensing image. Landsat satellite revisit cycle is 16 days 
while the Xianghe tower is still in cropland in recent 30 years. And the three Beijing rural stations are in evergreen broad leaved forest or grassland.

Data processing involves an initial quality control to eliminate any values that are clearly temporally or spatially discontinuous but with no physical significance. We then calculate the hourly, daily, and seasonal mean temperatures. The multiple linear regression is used to get the temperature trend.

\section{Inter-annual temperature variation}

Figure 2 shows the annual mean temperature anomalies derived from the mean data for 1984, 1987, and 1991-2009 from 8 of the 15 measurement levels of the Beijing tower. The pattern of variability among the levels is consistent. The average temperature anomalies show a large inter-annual variability in both summer (Fig. 2a) and winter (Fig. 2b).

The overall trend of recent 30 years is warming. The strongest warming is from 1980 s to 1990 s in summer (Fig. 2a). But the temperature decreased from the end of 1990 s to 2004 . The linear increase in the mean temperature recorded below $150 \mathrm{~m}$ during the summer is $0.632{ }^{\circ} \mathrm{C} /$ decade, exceeding $95 \%$ significance level. Moreover, a decadal variation is also evident. The temperature followed a decreasing trend from 1984 to 1992 and the lowest temperature was recorded in 1992. A fluctuating increase occurred from 1993 to 2000 in particular, consistent with the speed of urbanization in this area (Zheng and Liu 2008).

The warmest summers occurred in 1999 and 2000, which were $1.5{ }^{\circ} \mathrm{C}$ warmer in the boundary layer. The scale of the positive anomaly began to decline from 2001 to 2004 . The variation in summer temperature was relatively small between 2005 and 2009, although slight positive anomalies were recorded. Li et al (2009) assessed near-surface warming in Northeast China and found that, in summer, most positive anomalies were first evident in the early 1990s. They also indicated that the warmest years were 1998, 2000, 2001, and 2005. Temperature records from a height of $2 \mathrm{~m}$ at other stations in Beijing show similar features, and the warmest summer was recorded in 2000 in this dataset as well (Zhao et al. 2011). The temperature in these years exhibited striking positive anomalies in the tower data (Fig. 2a), in good agreement with these previous studies.

The summer warming trend was less well developed between 2003 and 2009 (Fig. 2a), but does this mean that the UHI effect was reduced in this period? The temperature trend comprises both large-scale variations and the UHI effect. In this study, we estimate the intensity of the UHI effect by subtracting the temperature variation at the three rural stations mentioned in last Section from the Beijing tower data. The difference between the temperature at a height of $8 \mathrm{~m}$ in Beijing and $2 \mathrm{~m}$ at the rural sites over the study period is shown in Fig. 2a to represent the UHI effect approximately. In the 1980s the difference was small, implying that the surface features surrounding the Beijing tower were similar in character to the rural areas. A marked UHI effect began in 1993, and its intensity gradually increased until 2000. There was little change in the intensity of the UHI from 2000 onwards, which implies that the UHI effect in Beijing had stabilized at around $1^{\circ} \mathrm{C}$ to $1.5^{\circ} \mathrm{C}$. The Beijing tower recorded the whole changing process from a rural landscape to an urban landscape.

Changes to the population, economy, buildings, and land use in a city are generally used as indicators of urbanization. The Beijing resident population, base construction investment, housing construction area, and road network have all followed a rising trend, with the fastest growth in the 1990s (Zheng and Liu 2008), and summer temperature profiles (Fig. 2a) are in good agreement with the progress of Beijing's urbanization. 
Temperature variability and the UHI effect recorded in winter over the study period differ from that observed during the summer (Fig. 2b). The mean linear warming trend recorded below $150 \mathrm{~m}$ is $0.555^{\circ} \mathrm{C} /$ decade, slower than the summer rate, and there is no apparent decadal variation. But the linear trend recorded at a height of $8 \mathrm{~m}$ is $0.708{ }^{\circ} \mathrm{C} /$ decade and $0.682{ }^{\circ} \mathrm{C} /$ decade in winter and summer respectively. The warming near the surface is slightly faster in winter. Moreover, the inter-annual variability is larger than that recorded during the summer, with the warmest winter anomaly being $+4{ }^{\circ} \mathrm{C}$ in 2002 and the coldest $-4{ }^{\circ} \mathrm{C}$ in 1987 (Fig. 2b), while the warmest and coldest summer anomalies were $+2{ }^{\circ} \mathrm{C}$ and $-2{ }^{\circ} \mathrm{C}$, respectively (Fig. 2a). Relatively low winter temperatures were recorded in 1987, 2000, 2001, and 2005, while relatively high values were recorded in 1999, 2002, and 2007. Compared with the average Beijing station records analyzed by Yan et al. (2009) and Zhao et al. (2011), the range of the inter-annual variability in the Beijing tower data is larger, but the inter-annual variations are similar. The relatively lower and higher mean temperatures occurred in the same winters found by Yan et al. (2009).

Figure $2 \mathrm{~b}$ also shows the difference between temperatures recorded at the tower and at the three rural stations as an estimate of the winter UHI effect. This method may induce some
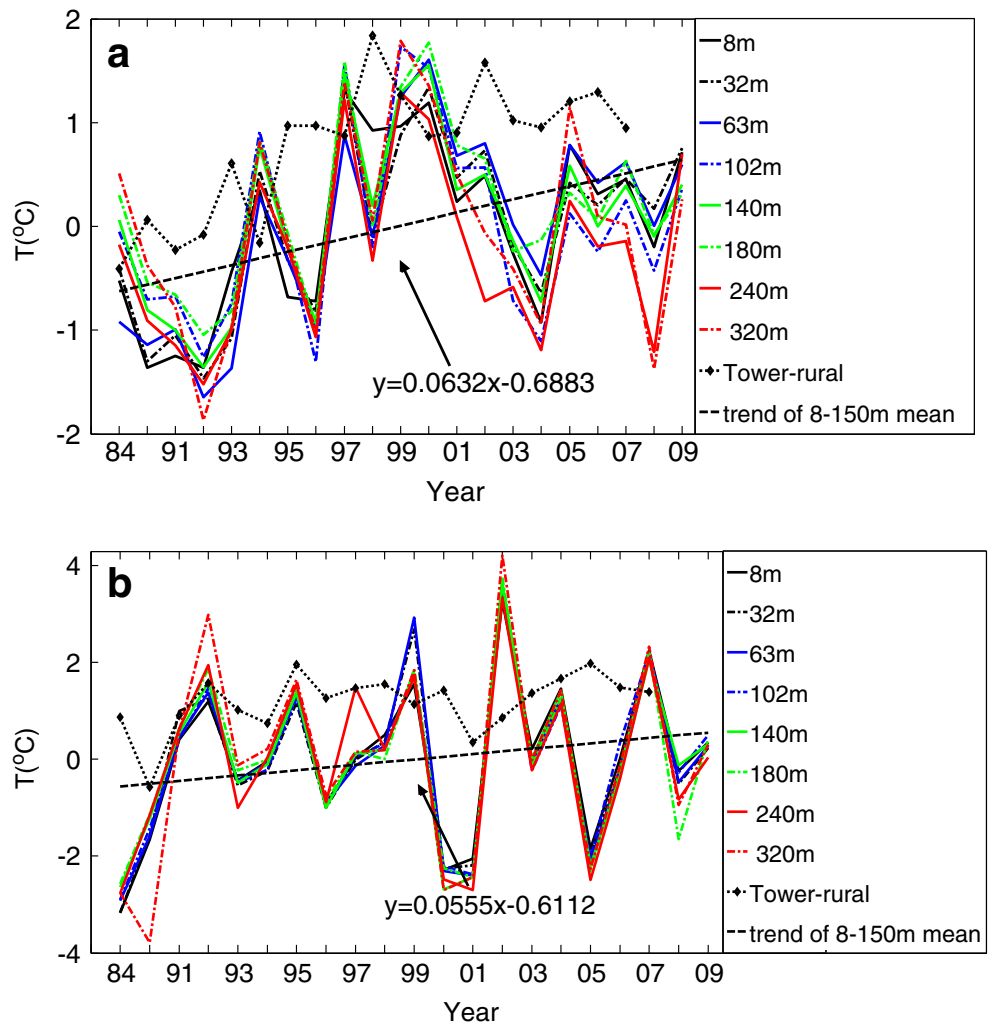

Fig. 2 Seasonal mean air temperature anomalies at alternating monitoring levels $(8-320 \mathrm{~m})$ of the Beijing meteorological tower for 1984, 1987, and 1991-2009 during a summer and b winter. Also shown is the difference between the temperature at a height of $8 \mathrm{~m}$ in Beijing, and the mean temperature from the three rural stations at a height of $2 \mathrm{~m}$, for 1984, 1987, and 1991-2007. The dotted lines show the temperature trends of the mean temperature below $150 \mathrm{~m}$ based on multiple linear regression 
biases, so the UHI effect was not exactly zero in 1980s. The UHI effect was almost constant, at $1.5^{\circ} \mathrm{C}$ to $2{ }^{\circ} \mathrm{C}$, larger than that recorded during the summer. This may be because the UHI effect that occurs during cold weather develops as a result of concentrated seasonal heating.

\section{Decadal change in vertical temperature profiles}

\subsection{Summer}

For simplicity we divide our data into three periods: the 1980s, 1990s, and 2000s. Figure 3 shows vertical profiles of the mean summer temperature at 05:00, 06:00, 07:00, 08:00, 17:00, 18:00, 19:00 and 20:00, which differ more than other hours among the three periods. The profiles during 1:00-4:00 were similar to that at 5:00 and were not shown. An night inversion existed below $50 \mathrm{~m}$ between 19:00 and 06:00 (LST) in the 1980s (Fig. 3a). The vertical temperature profiles from the Xianghe rural tower in 2009 (Fig. 3d) shown the inversion from 18:00 to the early morning 5:00 below $50 \mathrm{~m}, 1 \mathrm{~h}$ earlier that in 1980s, but the inversion height and during hours were similar to those from the $1980 \mathrm{~s}$ in Beijing. This suggests that in the 1980s the Beijing tower was located in an area with rural surface characteristics. However, the vertical temperature distributions from the 1990s and 2000s were different to those from the 1980s (Fig. 3a). The night inversions disappeared below $15 \mathrm{~m}$, the first second level in the 1990s (Fig. 3b) and 2000s except at 5:00 and 6:00, the period of the lowest temperature (Fig.3c). During the 2000s, a temperature inversion developed between 15 and $32 \mathrm{~m}$ during the night, but was shallower than in the $1980 \mathrm{~s}$. In general, it is radiation that causes inversions to develop below $50 \mathrm{~m}$ (Zhou 1994). Urban low-layer temperatures increase due to the release of urban heat storage, especially in clear sky (Bian et al. 2002). At night, the sensible heat exchange from the urban surface remains upwards. The radiation temperature inversion is changed through the transition from a suburban surface to one with features typical of an urban surface; consequently a groundlevel inversion rarely develops at night in urban areas.
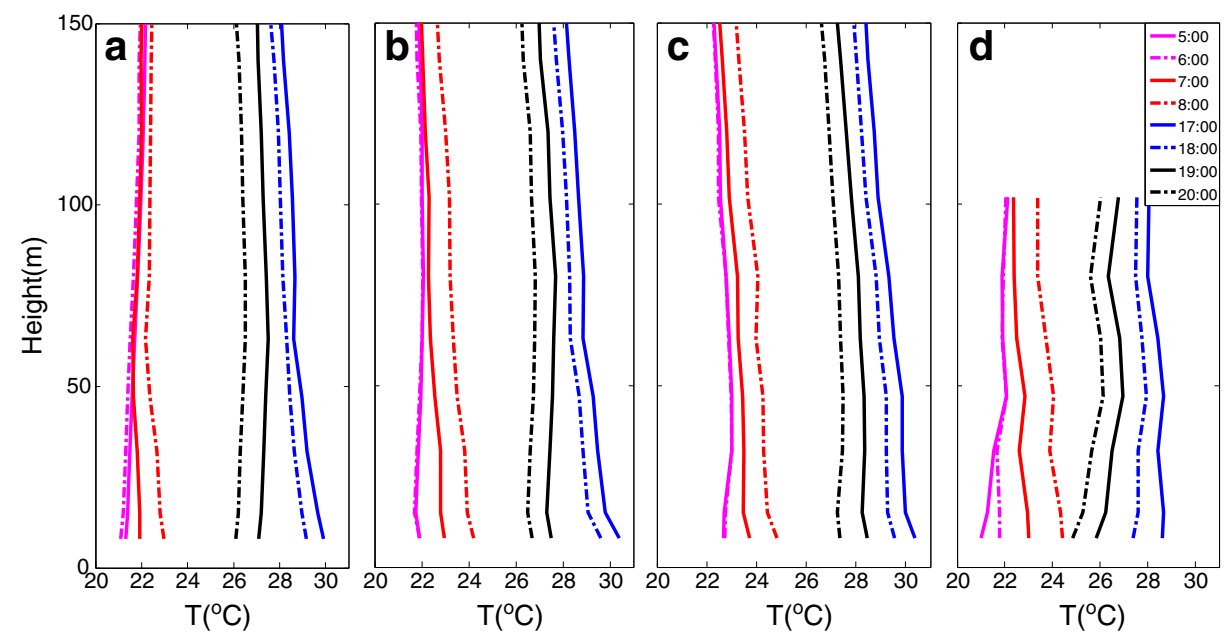

Fig. 3 Vertical profiles (from 8 to $150 \mathrm{~m}$ ) of summer hourly mean temperature for a Beijing in the 1980s, b Beijing in the 1990s, c Beijing in the 2000s, and d Xianghe in 2009 
Decadal mean surface temperatures followed a warming trend from the 1980 s to the 2000s. The temperature in daytime increased more markedly than in nighttime. In the vertical, the temperature increase was larger below $150 \mathrm{~m}$ than in the layers above (not shown). At a height of $8 \mathrm{~m}$, the temperature at $06: 00$ was $21.1^{\circ} \mathrm{C}$ in the $1980 \mathrm{~s}, 21.9^{\circ} \mathrm{C}$ in the 1990 s, and $22.7^{\circ} \mathrm{C}$ in the $2000 \mathrm{~s}$.

\subsection{Winter}

Figure 4 contains the vertical profiles of mean winter temperature across the same period. Warming occurred throughout the day from the $1980 \mathrm{~s}$ to the $1990 \mathrm{~s}$, but not much from the 1990 s to the $2000 \mathrm{~s}$, and the near-surface temperature changed from the 1990 s to the 2000s fewer than from 1980s to 1990s (Fig. 4b and c). An early morning temperature inversion was evident in Beijing in the 1980s and Xianghe in 2009 below $80 \mathrm{~m}$ (Fig. 4a and d). The height of the temperature inversion layer in the 2000s was $32 \mathrm{~m}$, much lower than that in the 1980s and 1990s (Fig. 4a and b). In a similar manner to the summertime trend, the inversion gradually became thinner over the past 30 years, suggesting that the stability of the surface layer weakened. Anthropogenic discharge from high-rise buildings may also lead to this phenomenon. A weaker inversion persisted from 20:00 to 06:00 of the following day in all periods. Above the inversion level, the temperature lapse rate was larger in the 2000s, which caused the temperature to be even lower than during the $1990 \mathrm{~s}$ above $100 \mathrm{~m}$, but still higher than in the 1980 s.

We haven't found that the temperature inversion was absent from the winter nearsurface layer in the 2000s, as it was during the summer in nighttime (Fig. $3 \mathrm{~b}$ and c), and this may be because the change in vertical temperature profile occurred below the monitoring height of $8 \mathrm{~m}$ (and so was not captured in the data). Alternatively, this seasonal difference may be due to the freezing of the ground surface during the winter, which reduces the difference in the surface heat flux and latent heat flux especially the latent heat flux (Zhang et al. 2009) between city surface and rural surface, so that the
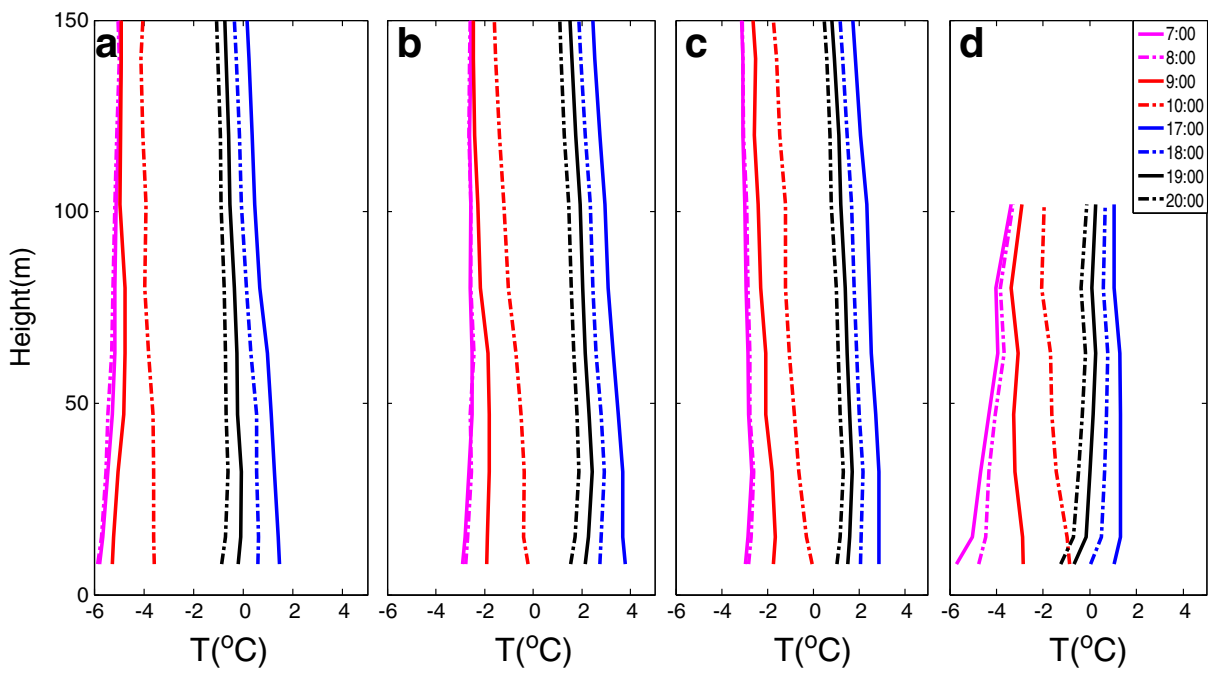

Fig. 4 As in Fig. 3 but for winter 
Table 1 Stable percentage in 32-47 $\mathrm{m}$ in Beijing and Xianghe in 2009

\begin{tabular}{lllllllll}
\hline Summer stable percentage(\%) & $5: 00$ & $6: 00$ & $7: 00$ & $8: 00$ & $17: 00$ & $18: 00$ & $19: 00$ & $20: 00$ \\
Xianghe & 72.62 & 70.73 & 74.07 & 83.95 & 67.12 & 60.56 & 67.61 & 70.0 \\
Beijing & 7.59 & 10.26 & 9.1 & 6.67 & 12.12 & 13.85 & 15.63 & 20.63 \\
Winter stable percentage(\%) & $7: 00$ & $8: 00$ & $9: 00$ & $10: 00$ & $17: 00$ & $18: 00$ & $19: 00$ & $20: 00$ \\
Xianghe & 90.38 & 84.31 & 90.00 & 51.02 & 88.09 & 87.80 & 90.00 & 87.18 \\
Beijing & 78.85 & 68.63 & 70.00 & 50.00 & 35.71 & 25.00 & 30.00 & 30.77 \\
\hline
\end{tabular}

difference in vertical structure near the rural and urban surfaces is smaller in winter than in summer.

We have shown that the temperature lapse rate altered from the 1980 s to the 2000 s. Such change in stability especially near the surface may be due to the impacts of the urbanization. To address such impacts, the general Richardson number (Rib) is calculated based on the hourly Beijing data and Xianghe data in 2009. Following Bi et al. (2005) we choose the Irwin's empirical formula (Irwin 1979) to classify the stability to get the percentage of the stable cases in $32-47 \mathrm{~m}$.

$$
\mathrm{Rib}=\frac{\mathrm{g}}{\bar{\theta}} \cdot \frac{\partial \bar{\theta}}{\partial \mathrm{z}} \cdot \frac{\overline{\mathrm{z}}^{2}}{\overline{\mathrm{u}}^{2}} \approx \frac{\mathrm{g}}{\bar{\theta}} \cdot \frac{\Delta \bar{\theta}}{\Delta \mathrm{z}} \cdot \frac{\left(\sqrt{\mathrm{z}_{1} \mathrm{z}_{2}}\right)^{2}}{\left(\sqrt{\mathrm{u}_{1} \mathrm{u}_{2}}\right)^{2}}
$$

Table 1 shows the results. The stable percentage of Xianghe is larger than Beijing especially in summer, which agrees with the above analysis. For example, $84 \%$ hours are stable in Xianghe and only $7 \%$ hours are stable in Beijing at 08:00. This result is consistent with the above analysis that the urbanization makes the surface layer unstable.

\section{Inter-decadal variation of the diurnal cycle}

\subsection{Summer}

Figure 5a shows the diurnal cycle of summer temperature for the 1980 s at the same alternating monitoring levels as in Fig. 2. Due to the small number of data points, the curve for the 1980s is not particularly smooth. The diurnal change in temperature follows a sinusoidal path. The maximum temperature $\left(\mathrm{T}_{\max }\right)$ appears around 14:00-15:00, and the minimum temperature $\left(\mathrm{T}_{\min }\right)$ around 05:00-06:00. One noticeable change over the three decades is that there was a deep temperature inversion in the early morning during the $1980 \mathrm{~s}$ (Fig. 5a), but not in the 2000s (Fig. 5b), consistent with the aforementioned analysis. In addition, the difference in $T_{\max }(T$ at 15:00) between adjacent layers in the 1990s (not shown) and the 2000s was much larger than the in the $1980 \mathrm{~s}$. The $\mathrm{T}_{\max }$ difference between $8 \mathrm{~m}$ and $320 \mathrm{~m}$ was $3.33{ }^{\circ} \mathrm{C}$ in the $1980 \mathrm{~s}$, but was $4.22{ }^{\circ} \mathrm{C}$ in the $2000 \mathrm{~s}$. This is because the urbanized surface is heated quickly by solar radiation during the day. Moreover, the enhanced near-surface friction intensifies surface sensible heating. Therefore, both the temperature at $8 \mathrm{~m}$ and the rate of vertical temperature decrease are increased. The higher temperature and the stronger turbulence occurred in the 1990s and 2000s (AJ-Jiboori and $\mathrm{Hu}, 2005)$, following the urbanization of the area surrounding the Beijing meteorological tower. This result is similar to the analysis of data from 1993 to 2003 by Xu et al. (2009). 

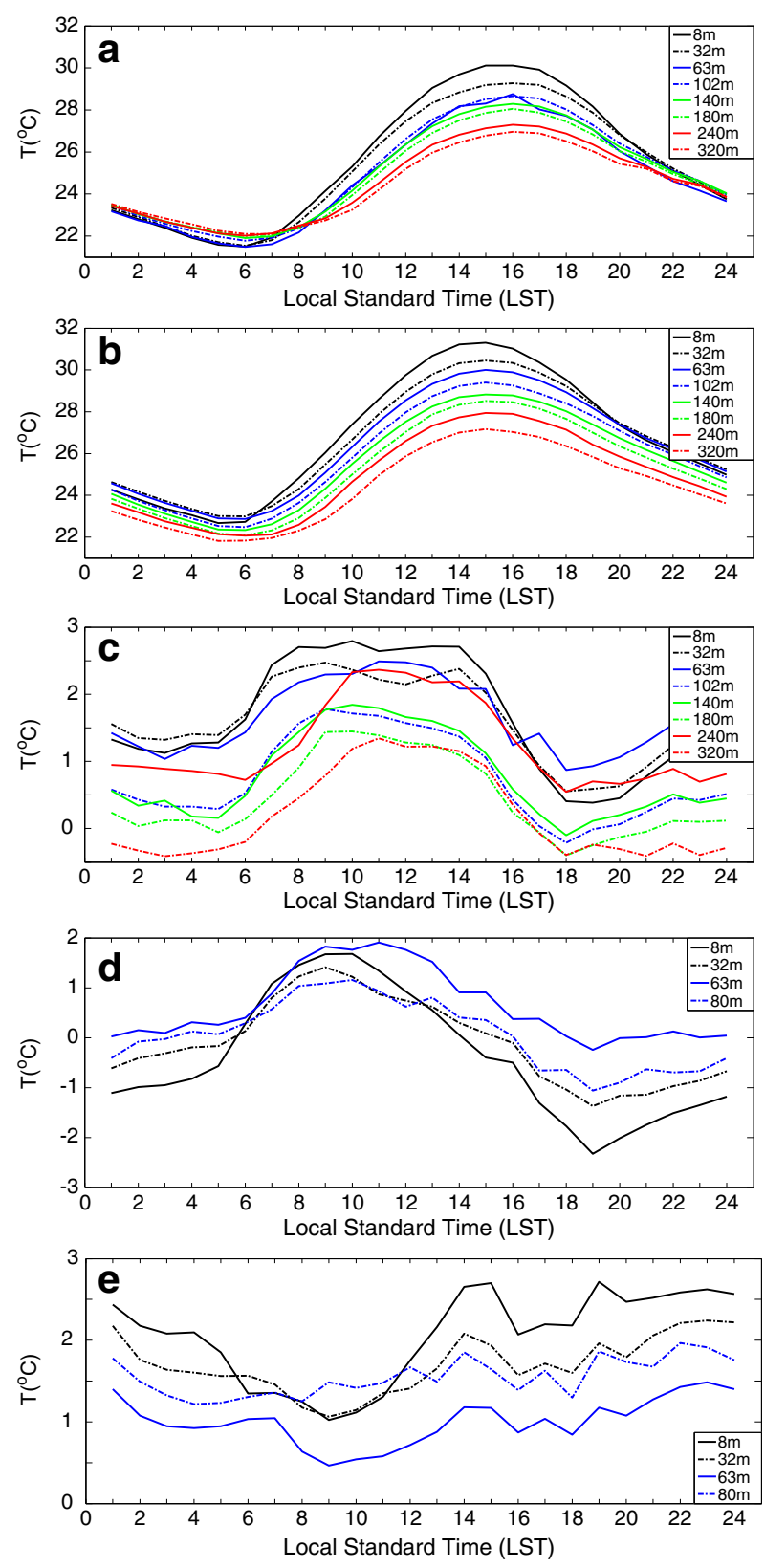

Fig. 5 Diurnal temperature variation during summer at a Beijing in the 1980s, b Beijing in 2000s, and c Beijing in the 2009 minus Beijing in the 1980s, d Xianghe in 2009 minus Beijing in the 1980s, and e Beijing in 2009 minus Xianghe in 2009

To quantitatively analyze the changes caused by urbanization and large-scale variation that includes the nature variability and global warming, we calculate the diurnal temperature differences among the Beijing tower in 1980s, 2009 and the Xianghe tower in 2009 (Fig. 5c-e). 
The general pattern in the change of the diurnal cycle between 2009 to 1980s (Fig. 5c) was with the minimum increase in the evening and maximum increase around noon near the surface. From 1980 s to 2009, the temperature increased at all levels and all times in a day except the top level in nighttime, particularly from sunrise to 15:00. Such change is from both urbanization and large-scale variation. It is interesting to note that the change caused by large-scale variation shows the same maximum increase during the sunrise to $3 \mathrm{pm}$ but with 1 degree less in intensity (Fig. 5d). The urbanization mainly contributes to the temperature increase in the afternoon and nighttime (Fig. 5e), which is consistent with the UHI impacts from Miao et al. (2009). The stronger UHI effect in nighttime (Fig. 5e) is agreement with the results from field experiments that the influence of urbanization on air temperature is strongest in calm and cloudless night (Oke 1982; Johnson et al. 1991). But at a higher level (63 $\mathrm{m}$ and $80 \mathrm{~m}$ ), the UHI impact goes steady and has shown a much weaker diurnal cycle than that near the surface. Comparing Fig. 5e to Fig. 5d, the intensity of the maximum increase in the diurnal cycle from the urbanization is slightly stronger than that from the large-scale variation. Additionally the urbanization dominates the increase in afternoon and nighttime, and also dominates the daily mean warming of the near-surface temperature.

\subsection{Winter}

As in summer, the first two panels of Fig. 6 show the diurnal cycle of winter temperature in the $1980 \mathrm{~s}$ and 2000s. The diurnal cycle of winter temperature follows a similar sinusoidal pattern to that observed during the summer in these two periods. The inversion layer developed during the early morning in the both decades, but its thickness gradually was reduced from the 1980 s to the 2000 s.

$T_{\max }$ occurred between 14:00 and 15:00, and $T_{\min }$ in the period 07:00-08:00. As in the summer, the difference in $\mathrm{T}_{\max }$ between adjacent layers increased from the 1980s onwards. The $\mathrm{T}_{\max }$ difference between $8 \mathrm{~m}$ and $320 \mathrm{~m}$ was $2.80^{\circ} \mathrm{C}$ in the $1980 \mathrm{~s}$ (Fig. 6a), and $3.55^{\circ} \mathrm{C}$ in the 2000 s (Fig. 6b), means the mixing of the boundary layer was enhanced during the daytime.

The main change in the diurnal cycle from 1980s to 2009 (Fig. 6c), and the changes either caused by the large-scale variation (Fig. 6d) or by the urbanization (Fig. 6e) in winter are similar to those in summer respectively. The largest increase in temperature happens after the sunrise to the 15:00 in a day (Fig. 6c), which is again mainly caused by the large-scale variation (Fig. 6d). But warming during the winter (Fig. 6d) is stronger defined than in summer (Fig. 5d), while the UHI impacts are almost the same in winter as in summer (Figs. 5e and 6e). As a result, the urbanization dominates the warming in whole day except morning.

\section{Summary}

The Beijing meteorology tower is located in an area of the city that has changed from a suburban to an inner city landscape over the past 30 years. In this study, based on data from the Beijing meteorology tower and a rural tower, inter-annual and inter-decadal temperature variations have been analyzed to investigate the impact of urbanization. Our main findings are summarized as follows.

Within a background of global warming, the temperature recorded at the Beijing meteorology tower has followed a warming trend over the past three decades. The incremental rate was $0.682{ }^{\circ} \mathrm{C} / \mathrm{decade}$ during the summer and $0.708{ }^{\circ} \mathrm{C} / \mathrm{decade}$ in the winter at the height 

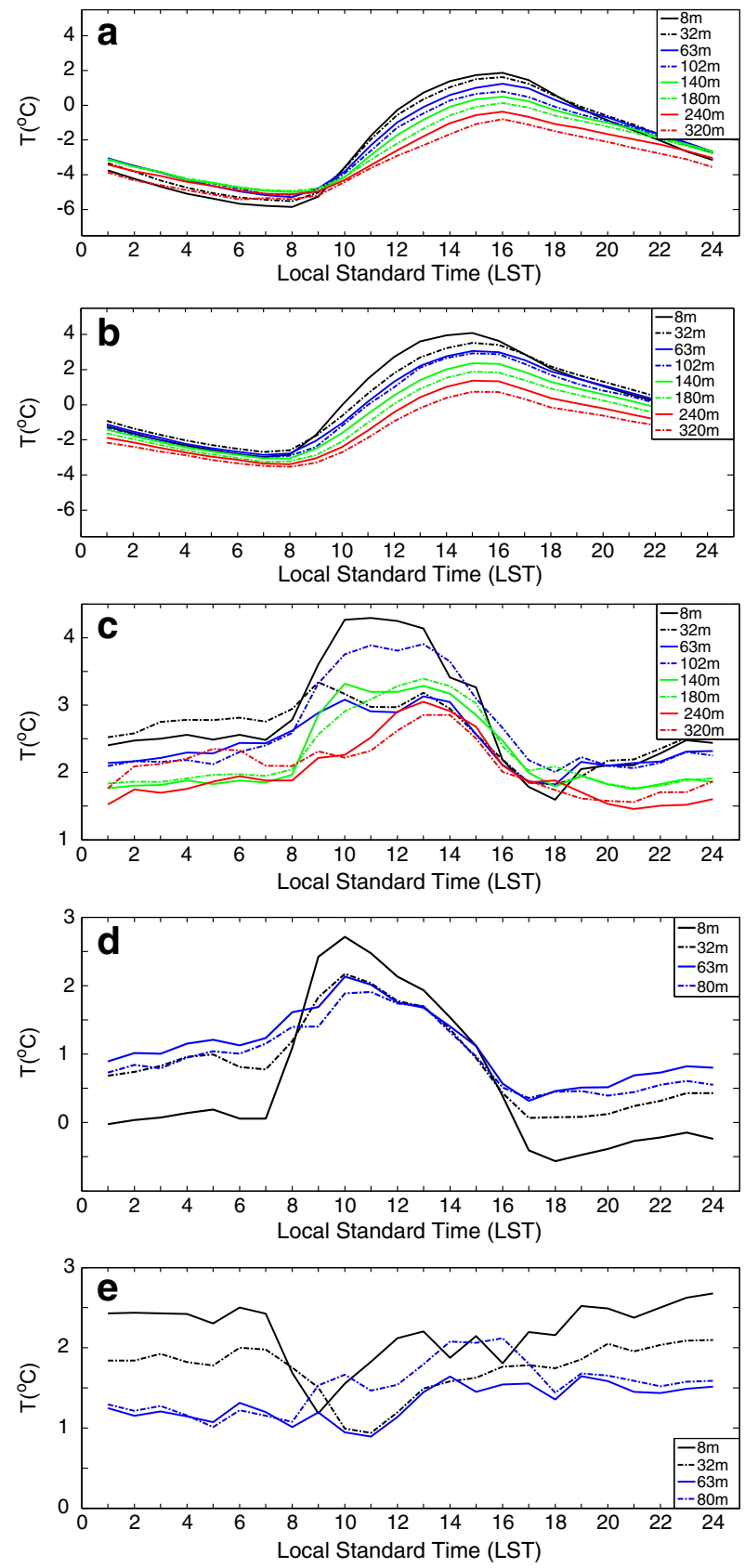

Fig. 6 As in Fig. 5 but for winter

of $8 \mathrm{~m}$. The UHI effect occurred for the first time at the beginning of the 1990s as a result of urbanization. The intensity of the UHI effect was $1{ }^{\circ} \mathrm{C}$ to $1.5^{\circ} \mathrm{C}$ during the summer, and $1.5^{\circ} \mathrm{C}$ to $2{ }^{\circ} \mathrm{C}$ in the winter. 
The inter-decadal temperature increased gradually over the monitoring period, with the most significant increase from the 1980s to the 1990s. The increase in nighttime temperatures was the most significant, especially during the winter. A change in temperature stratification was evident during both the summer and winter periods. Consequently, the nighttime temperature inversion layer was thinned in winter of the 1990s and 2000s, and completely absented below $15 \mathrm{~m}$ in summer. The height of the temperature inversion layer decreased in the lower layers because turbulent mixing was strengthened due to the release of heat stored by the urban surface.

The temperature changes in Beijing from 1980s to 2000s are caused by urbanization and large-scale variation that includes the nature variability and global warming. The diurnal change in temperature in summer shows a maximum increase from sunrise to the early afternoon, which is mainly caused by the large-scale variation in both the summer and winter. The urbanization mainly contributes to the temperature increase in the afternoon and nighttime, and dominates the increase in daily mean near-surface temperature.

The atmosphere is directly influenced by changes in surface heat flux caused by land use and land cover change. Observations of surface flux turbulence at the Beijing and Xianghe towers began in 2005 and 2009, respectively. This ongoing work will analyze the flux differences between urban and rural areas to further improve our understanding of the impact of urbanization.

Acknowledgments The authors would like to thank three anonymous referees for many constructive comments on this study. This work was financed by the National Key Basic Research and Development Project of China (2010CB428502).

Open Access This article is distributed under the terms of the Creative Commons Attribution License which permits any use, distribution, and reproduction in any medium, provided the original author(s) and the source are credited.

\section{References}

Al-Jiboori MH, Hu F (2005) Surface roughness around a 325-m meterorological tower and its effect in urban turbulence. Adv Atmos Sci 22(4):595-605. doi:10.1007/BF02918491

Bi X, Liu F, Wu D (2005) Comparision of some limit for stability classification. J Trop Meteorol 21(4):402

Bian L, Cheng Y, Wang X, Gan Z, Wang Y, Lu L (2002) Observation study of wind and temperature profiles of urban boundary layer in Beijing winter. J Appl Meteorol Sci 13:13-25

Bornstein RD (1968) Observations of the urban heat island effect in New York City. J Appl Meteorol 7(4):575-582. doi:10.1175/1520-0450(1968) 007

Dai Y, Liu Y, Zhou L (2011) Observation analysis of urbanization effect on surface air temperature trends in East China. J Meteorol Sci 31(4):365-371

$\mathrm{Hu}$ Y, Dong W, He Y (2010) Impact of land surface forcings on mean and extreme temperature in eastern China. J Geophys Res 115(D19). doi:10.1029/2009jd013368

Irwin JS (1979) Estimating plume dispersion- a recommended generalized scheme[A]. Fourth Symposium on Turbulence, Diffusion, and Air Pollution ( Reno, Nev ) AMS, Boston. 62-69

Johnson GT, Oke TR, Lyons TJ et al (1991) Simulation of surface urban heat islands under "ideal" conditions at night. Part 1: theory and tests against field data. Bound-Layer Meteorol 56:275-294

Kalnay E, Cai M (2003) Impact of urbanization and land-use change on climate. Nature 423(6939):528-531

Kalnay E, Cai M, Li H, Tobin J (2006) Estimation of the impact of land-surface forcings on temperature trends in eastern United States. J Geophys Res 111(D6). doi:10.1029/2005jd006555

Li Q, Li W, Si P, Xiaorong G, Dong W, Jones P, Huang J, Cao L (2009) Assessment of surface air warming in northeast China, with emphasis on the impacts of urbanization. Theor Appl Climatol 99(3-4):469-478. doi:10.1007/s00704-009-0155-4

Miao S, Chen F, LeMone MA, Tewari M, Li Q, Wang Y (2009) An observational and modeling study of characteristics of urban heat island and boundary layer structures in Beijing. J Appl Meteorol Climatol 48(3):484-501. doi:10.1175/2008jamc1909.1 
Oke TR (1982) The energetic basis of the urban heat island. Q J R Meteorol Soc 108:1-24

Oke TR (1995) The heat island of the urban boundary layer: characteristics, causes and effects. Wind Climate in Cities

Peng Z, Hu F (2006) A study of the influence of urbanization of Beijing on the boundary wind structure. Chin J Geophys 49(6):1608-1615 (in Chinese)

Ren GY, Chu ZY, Chen ZH, Ren YY (2007) Implications of temporal change in urban heat island intensity observed at Beijing and Wuhan stations. Geophys Res Lett 34(5). doi:10.1029/2006g1027927

Vickers D, L.Mahrt (2004) Evaluating formulations of stable boundary layer height. J Appl Meteorol 43(1736-1749). doi:10.1175/JAM2160.1

Wang K, Wang J, Wang P, Sparrow M, Yang J, Chen H (2007) Influences of urbanization on surface characteristics as derived from the Moderate-Resolution Imaging Spectroradiometer: a case study for the Beijing metropolitan area. J Geophys Res 112(D22). doi:10.1029/2006jd007997

$\mathrm{Xu}$ Y, Liu S, Hu F (2009) Influence of Beijing urbanization on the characteristics of atmospheric boundary layer. Chin J Atmos Sci 33(4):859-867 (in Chinese)

Yan Z, Li Z, Li Q, Jones P (2009) Effects of site change and urbanisation in the Beijing temperature series 1977-2006. Int J Climatol 30(8):1226-1234. doi:10.1002/joc.1971

Zhang CL, Chen F, Miao SG, Li QC, Xia XA, Xuan CY (2009) Impacts of urban expansion and future green planting on summer precipitation in the Beijing metropolitan area. J Geophys Res 114(D2). doi:10.1029/ 2008jd010328

Zhang J, Hou Y, Li G, Yan H, Yang L, Yao F (2005) The diurnal and seasonal characteristics of urban heat island variation in Beijing city and surrounding areas and impact factors based on remote sensing satellite data. Sci China Ser D Earth Sci 48(D1):220-229. doi:10.1360/05yd0026

Zhao N, Liu S, Yu H (2011) Urbanization effects on local climate in Beijing in recent 48 years. Chin J Atmos Sci 35(2):373-385 (in Chinese)

Zheng S, Liu S (2008) Urbanization effect on climate in Beijing. Clim Environ Res 13(2):123-133

Zhou S (1994) Urban Climatology. China Meteorological Press, China 